Journal of Healthcare Technology and Medicine Vol. 5 No. 2 Oktober 2019

Universitas Ubudiyah Indonesia

e-ISSN : 2615-109X

\title{
Motivasi Remaja Melakukan Kegiatan Senam Jantung Sehat Pada Hari Minggu Di Lapangan Blang Padang Banda Aceh
}

\section{Motivation of Youth to Conduct Healthy Heart Gymnastics Activities on Sundays at Blang Padang Field in Banda Aceh}

\author{
Syarifuddin ${ }^{* 1}$ \\ ${ }^{1}$ Program Studi Agribisnis, Universitas Abulyatama, Jln. Blang Bintang Lama, Km. 8,5, Aceh Besar, 23373 \\ Indonesia \\ *Koresponden Penulis : syarifuddinhasan767@gmail.com
}

\begin{abstract}
Abstrak
Penelitian untuk mengetahui motivasi remaja melakukan senam jantung sehat, baik intrinsik maupun ekstrinsik. Penelitian ini bersifat deskriptif, metode Simpel Random Sampling, berjumlah 65 orang berusia 10-19 tahun, Analisa data univariat, format jawaban Guttman. Hasil penelitian, motivasi instrinsik remaja dalam melakukan senam jantung sehat katagori tinggi 53,84\%, katagori rendah 46,15\%. Motivasi ekstrinsik katagori tinggi 46,15\%, katagori rendah 53,85\%. Secara umum motivasi remaja melakukan senam jantung sehat, katagori tinggi 41,54\%, katagori rendah 58,46\%. Diharapkan adanya motivasi remaja dalam melakukan senam jantung sehat, agar dapat hidup sehat jasmani dan rohani.
\end{abstract}

Kata kunci : Senam, Jantung, Sehat.

\section{Abstract}

Research to determine the motivation of adolescents to do healthy heart gymnastics, both intrinsic and extrinsic. This research is a descriptive, simple random sampling method, totaling 65 people aged 10-19 years, univariate data analysis, Guttman's answer format. The results of the study, intrinsic motivation of adolescents in doing healthy heart exercises high category $53.84 \%$, low category $46.15 \%$. High category of extrinsic motivation is $46.15 \%$, low category is $53.85 \%$. In general, adolescent motivation to do healthy heart exercises, high categories $41.54 \%$, low categories $58.46 \%$. It is expected that the motivation of adolescents in doing heart healthy gymnastics, in order to be able to live physically and mentally healthy.

Keywords: Gymnastics, Heart, Healthy. 
Journal of Healthcare Technology and Medicine Vol. 5 No. 2 Oktober 2019

Universitas Ubudiyah Indonesia

e-ISSN : 2615-109X

\section{PENDAHULUAN}

Pemerintah dalam membangun masyarakat sehat diperlukan tindakan penekanan atau penurunan nangka kematian. Kebijakan penurunan angka kematian dapat dilakukan dengan berbagai cara, antara lain adalah menerapkan pola hidup sehat. Di beberapa belahan dunia, terutama negara maju dan negara berkembang akibat tidak ada penerapan pola hidup sehat tercatat angka kematian hampir $12 \%$, dan gaya hidup ini sulit untuk dirubah (Ahyarmuchlis, 2016).

Dilansir dari jurnal medicine of sporty yang di publikasikan oleh Marchlison (Dwidaya, 2016) menunjukkan rendahnya keinginan remaja yang berpartisipasi dalam hal kegiatan berolahraga. Data lain di dapatkan di negara maju Jepang hanya $12 \%$ dari jumlah remaja yang ada di salah satu sekolah terkemuka di Jepang yang memiliki minat dalam hal berolahraga (Adelia, 2016).

Pada studi yang di publikasikan oleh (Ducth Group Elsimer, 2015) dalam jurnal preventif medicine, peneliti melibatkan 248 partisipasi penduduk Jerman yang hidup di kota dengan kesibukan yang ekstra, mereka rata-rata berusia remaja, tidak pernah berolah raga, mengkonsumsi makanan cepat saji dan juga pola hidup yang buruk selama 2 tahun peneliti mencatat $25 \%$ partisipan meninggal dunia. Mereka cenderung menderita obesitas, gangguan jantung, kanker dan juga tekanan darah tinggi (Halim,2015).

Usia harapan hidup masyarakat Indonesia pada tahun 2015 mengalami peningkatan, banyak masyarakat terutama remaja yang mengikuti gaya hidup sehat dan membatasi makanan ringan yang membahayakan. Periode tahun 2016 usia harapan hidup mencapai 52,2\%, tahun 2010 mencapai 48\%, tahun 2005 mencapai 42,2 \% . Periode tahun 2016 jumlah remaja yang ada di Indonesia mencapai 7.998.543 atau sebesar 5,45\% dari jumlah penduduk, periode 2017 jumlah remaja mencapai 11.2.77.55.7 atau sebesar 6,39\% dari jumlah penduduk, sedangkan perkiraan periode tahun 2020 jumlah penduduk remaja mencapai 54.4.55.7 atau sebesar 20\% (Menteri Koordinator Kesejahteraan Rakyat,2016), dalam (Yunistatih, 2018).

Badan Sensus Penduduk Provinsi Nanggroe Aceh Darussalam mencatat jumlah remaja yang ada di Aceh sebanyak 304.281 jiwa. Dari hasil wawancara peneliti terhadap pengelola senam jantung sehat yang ada di Lapangan Blang Padang Banda Aceh kurangnya motivasi remaja sehingga di dalam barisan di dominasi oleh orang dewasa. Remaja yang hadir di Lapangan Blang Padang cenderung tidak memiliki motivasi yang kuat sehingga enggan untuk melalukan kegiatan senam tersebut. 
Journal of Healthcare Technology and Medicine Vol. 5 No. 2 Oktober 2019

Universitas Ubudiyah Indonesia

e-ISSN : 2615-109X

Berdasarkan hasil observasi peneliti di lapangan Blang Padang Banda Aceh sedikit remaja yang ingin melakukan kegiatan senam yang diadakan di lapangan Blang Padang Banda Aceh, banyak remaja yang hanya berkumpul di lapangan Blang Padang bersama teman-temannya baik untuk sekedar berfoto, bermain dan sekedar lari pagi bersama temantemannya. Di dalam barisan senam jantung sehat terlihat lebih didominasi oleh orang dewasa. Berdasarkan hasil wawancara peneliti terhadap beberapa remaja yang ada di Lapangan Blang Padang di hari Minggu 8 dari 10 remaja mengatakan mereka hanya sekedar datang, lari pagi, dan sarapan pagi bersama temannya tanpa mengikuti senam jantung sehat.

Mengacu pada manfaat senam jantung sehat bagi masyarakat Banda Aceh sangat baik dan positif bagi tubuh seseorang, alangkah baiknya kegiatan ini juga diikuti oleh remaja yang ada di Banda Aceh. Mengingat kegiatan senam ini sangat positif terlebih kegiatan ini hanya diadakan di hari Minggu saja dimana waktu luang dari segala kegiatan yang ada. Salah satu tujuan dari kegiatan senam jantung sehat yakni melancarkan sirkulasi darah keseluruh tubuh yang akan menjadikan tubuh menjadi lebih bugar dan sehat.

Berdasarkan latar belakang permasalahan yang dikemukakan maka penulis tertarik untuk melakukan penelitian dengan judul "Motivasi Remaja Melakukan Kegiatan Senam Jantung Sehat Pada Hari Minggu di Lapangan Blang Padang Banda Aceh". Tujuan penelitian ini adalah untuk mengetahui motivasi remaja dalam melakukan kegiatan senam jantung sehat dilapangan Blang Padang Banda Aceh.

\section{METODE PENELITIAN}

Penelitian ini bersifat deskriptif. Teknik sampling yang digunakan dalam metode penelitian ini adalah Simpel Random Sampling, dengan jumlah sampel 65 orang yaitu remaja yang berusia 10 - 19 tahun. Tempat penelitian dilaksanakan di Lapangan Blang padang Banda Aceh. Penelitian ini dilaksanakan pada bulan Agustus 2019 di Lapangan Blang Padang Banda Aceh. Analisa data yang digunakan pada penelitian ini adalah analisis univariat. Pengukuran variabel menggunakan format jawaban Guttman,

\section{HASIL DAN PEMBAHASAN}

1. Motivasi Intrinsik

Motivasi intrinsik remaja dalam melakukan kegiatan senam jantung sehat pada hari Minggu di lapangan Blang Padang Banda Aceh Tahun 2019, dapat dilihat pada tabel berikut. 
Journal of Healthcare Technology and Medicine Vol. 5 No. 2 Oktober 2019

Universitas Ubudiyah Indonesia

e-ISSN : 2615-109X

Tabel 1. Distribusi Frekuensi Motivasi Intrinsik Remaja Dalam Melakukan Kegiatan

Jenam Jantung Sehat Pada Hari Minggu di Lapangan Blang Padang Banda Aceh Tahun $2019(\mathrm{n}=65)$

\begin{tabular}{cccc}
\hline No. & Katagori & Frekuensi & Persentasi \\
\hline 1. & Tinggi & 35 & 53,84 \\
2. & Rendah & 30 & 46,15 \\
& & & 100,00
\end{tabular}

Sumber : Data Primer (Diolah, Agustus, 2019).

Dari Tabel 1 diatas dapat dilihat bahwa dari 65 responden ternyata motivasi intrinsik remaja dalam melakukan kegiatan senam jantung sehat berada dalam katagori Tinggi berjumlah 35 responden $(53,84 \%)$ dan kagori rendah 46,15 \%. Hal ini berdasarkan pengolahan data perolehan data skor total 236 sehingga nilai rata-rata $\dot{x}=3$ selanjutnya dikatagorikan apabila Tinggi $x \geq 3$ dan Rendah $x<3$.

\section{Motivasi Ekstrinsik}

Motivasi ekstrinsik remaja dalam melakukan kegiatan senam jantung sehat pada hari Minggu di lapangan Blang Padang Banda Aceh Tahun 2019, dapat dilihat pada tabel berikut.

Tabel 2. Distribusi Frekuensi Motivasi Ekstrinsik Remaja Melakukan Kegiatan Senam Jantung Sehat di Lapangan Blang PadangBanda Aceh Tahun $2019(\mathrm{n}=65)$

\begin{tabular}{llcc}
\hline No. & Katagori & Frekuensi & Persentase \\
\hline 1. & Tinggi & 30 & 46,15 \\
2. & Rendah & 35 & 53,85 \\
\hline & Total & 65 & 100,00 \\
\hline
\end{tabular}

Sumber : Data Primer (Diolah, Agustus, 2019)

Dari Tabel 2. diatas dapat dilihat bahwa dari 65 responden ternyata motivasi entrinsik remaja dalam melakukan kegiatan senam jantung sehat berada dalam katagori Rendah berjumlah 35 responden $(53,85 \%)$ dan katagori tinggi 46,15\%. Hal ini berdasarkan hasil pengolahan data perolehan data skor total 227 sehingga nilai rata-rata $\dot{x}=3$ selanjutnya dikatagorikan apabila Tinggi $x \geq 3$ dan Rendah $x<3$.

3. Motivasi Remaja Melakukan Senam Jantung Sehat.

Untuk melihat secara umum motivasi remaja dalam melakukan kegiatan senam jantung sehat dapat dilihat pada Tabel berikut. 
Journal of Healthcare Technology and Medicine Vol. 5 No. 2 Oktober 2019

Universitas Ubudiyah Indonesia

e-ISSN : 2615-109X

Tabel 3. Distribusi Frekuensi Berdasarkan Motivasi Remaja Usia Dalam Melakukan

Kegiatan Senam Jantung Sehat Pada Hari Minggu di Lapangan Blang Padang Banda Aceh Tahun $2019(n=65)$

\begin{tabular}{llcc}
\hline No. & Katagori & Frekuensi & Persentase \\
\hline 1. & Tinggi & 27 & 41,54 \\
2. & Rendah & 38 & 58,46 \\
\hline Total & & 65 & 100,00
\end{tabular}

Sumber : Data Primer (diolah, Agustus 2019)

Dari Tabel 3 diatas dapat dilihat bahwa dari 65 responden ternyata motivasi remaja dalam melakukan kegiatan senam jantung sehat berada dalam katagori Rendah berjumlah 38 responden (58,46\%) dan katagori tinggi 41,54\%. Hal ini berdasarkan hasil pengolahan data perolehan skor total 695 sehingga nilai rata-rata $\dot{x}=10$ selanjutnya dikatagorikan apabila Tinggi $x \geq 10$ dan Rendah $x<10$.

\section{Pembahasan}

1. Motivasi Intrinsik Remaja Dalam Melakukan Kegiatan Senam Jantung Sehat

Alasan motivasi remaja dalam katagori tinggi, karena remaja memiliki motivasi atau dorongan yang ada di dalam dirinya sendiri. untuk melakukan kegiatan senam jantung sehat. Menurut (Muchlis, 2015), secara garis besar motivasi yang baik ialah motivasi yang berasal dari diri sendiri tanpa ada paksaan dari pihak luar maupun stimulus eksternal yang mempengaruhi motivasi tersebut, ini dapat dibuktikan motivasi yang berasal dari diri sendiri (internal) akan memberikan dampak yang lebih lama dan individu dapat melakukan kegiatan secara maksimal sesuai harapan yang ingin dicapai. Seperti dikemukakan oleh Wanda (2016), Motivasi intrinsik yang besar akan muncul apabila terdapat rangsangan yang baik dan juga kuat dari diri sendiri yang dapat menjadikan perbuatan seseorang lebih tertata dan terarah dengan baik, ini dikarnakan seseorang akan menjadi lebih mencintai yang dilakukan karena keinginan diri individu itu sendiri. Terdapat beberapa faktor pendukung yang menjadi alasan seseorang melakukan kegiatan karena keinginannya sendiri diantaranya hobi, kebutuhan, kepuasan dan juga harapan individu. Hal ini juga sesuai dengan hasil penelitian (Andelia 2016), mengenai gambaran motivasi remaja tentang olah raga, dimana terdapat 36 responden hasil penelitian menunjukkan bahwa berada dalam kategori baik berjumlah 26 orang (72.2\%), angka ini menunjukkan bahwa motivasi remaja dalam kategori tinggi. Menurut (Kusumah 2014), kebutuhan setiap individu akan kesenangan yang mereka butuhkan berbeda-beda karena setiap individu memiliki kesenangan dan juga batas kesenangan yang berbeda-beda sehingga jarang sekali menunjukkan batas minat individu dalam range yang sama. Ini sama 
Journal of Healthcare Technology and Medicine Vol. 5 No. 2 Oktober 2019

Universitas Ubudiyah Indonesia

e-ISSN : 2615-109X

seperti di dalam keluarga yang terdapat ayah, ibu, dan anak-anak yang memiliki minat yang berbeda-beda meskipun mereka berada di dalam satu rumah yang sama. Menurut asumsi peneliti maka peneliti beranggapan bahwa tingkat motivasi intrinsik berada dalam katagori tinggi dikarnakan berhasilnya promosi kesehatan yang dikemukakan oleh tim kesehatan sehingga memberikan keinginan yang besar bagi individu untuk selalu menjaga kebugaran dirinya dan kesehatan anggota keluarga. Masyarakat pun telah mengetahui maksud dengan adanya program-program kesehatan yang baik akan meningkatkan kualitas kesehatan anggota keluarganya. Sehingga masyarakat sudah mulai sadar dan menjaga kesehatan dirinya sendiri dengan baik dan benar. Motivasi intrinsik alangkah baiknya terus dikembangkan ini sangat memberikan dampak yang baik bagi individu itu sendiri selain motivasi intrinsik memberikan konstribusi yang baik dan lama, motivasi yang berasal dari diri sendiri cenderung akan membuahkan hasil maksimal disetiap kegiatan yang dilakukan.

2. Motivasi Ekstrinsik Remaja Dalam Melakukan Kegiatan Senam Jantung Sehat.

Pada saat dilakukan penelitian peneliti mendapatkan banyak remaja yang mengeluhkan malas melakukan kegiatan senam jantung sehat dikarenakan ajakan teman dekat sehingga sulit untuk menghindar. Hal ini sesuai teori yang dikemukakan oleh (Muchlis 2015), ia mengatakan bahwa motivasi ekstrinsik sangat kecil memberikan dampak yang besar bagi individu itu sendiri, ini dikarenakan motivasi eksternal atau ekstrinsik ialah motivasi yang berasal dari dorongan pihak luar yang terkadang memaksa keinginan individu tersebut. Menurut (Sudoyo, 2016), motivasi ekstrinsik ialah motivasi yang memberikan dukungan yang berasal dari luar yang menjadikan seseorang terangsang untuk melakukan kegiatan yang diinginkan. Semakin tinggi motivasi ekstrinsik yang diberikan kepada pihak luar akan memberikan pengaruh besar terhadap individu tersebut. Motivasi ekstrinsik berdasarkan faktor pendukung ialah lingkungan dimana tempat seseorang berada dengan berbagai kegiatan yang dilakukan secara berulang-ulang, dirangsang, diawali dan kemudian diarahkan. Perilaku atau aktivitas yang ada pada setiap individu tidak timbul dengan sendirinya tetapi sebagai akibat dan stimulus atau rangsangan dari luar, dan motivasi yang menstimulus seseorang paling besar biasanya adalah faktor eksternal yaitu lingkungan (Sardiman, 2017). Penelitian yang telah diteliti oleh (Suniyanti, 2017 mengenai pengetahuan remaja tentang motivasi ekstrinsik remaja dalam melakukan kegemaran, dimana terdapat 45 responden hasil penelitian menunjukkan bahwa motivasi ekstrinsik berada pada kategori rendah berjumlah 16 orang $(48,5 \%)$, angka ini menunjukkan bahwa motivasi esktrinsik remaja berada pada kategori rendah. Menurut asumsi penelitian maka peneliti beranggapan bahwa tingkat 
Journal of Healthcare Technology and Medicine Vol. 5 No. 2 Oktober 2019

Universitas Ubudiyah Indonesia

e-ISSN : 2615-109X

motivasi ekstrinsik berada dalam kategori rendah karena stimulus yang diberikan pihak luar sangatlah rendah ini berkaitan dengan lingkungan Blang Padang tidak terdapat pembaharuan sehingga pemandangan yang membosankan yang menjadikan remaja jenuh mendatangi lapangan tersebut. Motivasi ekstrinsik dapat memberikan dampak yang tinggi, apabila setiap individu terus diberikan stimulus yang baik dari luar sehingga individu terus terpacu dalam melakukan kegiatan tersebut, stimulus akan memberikan dampak yang baik apabila di lakukan secara baik dan secara terus menerus.

\section{Motivasi Remaja Dalam Melakukan Kegiatan Senam Jantung Sehat}

Pada saat dilakukan penelitia mendapatkan bahwa remaja mengeluh malas melakukan kegiatan senam jantung sehat di lapangan Blang Padang yang diadakan rutin setiap minggu nya karena membosankan, gerakan yang cenderung ringan bagi remaja juga menjadi alasan remaja tersebut. Hal ini sesuai dengan teori yang dikemukakan (Wanda 2016), ia menjelaskan bahwa remaja adalah individu yang cepat merasakan kebosanan yang tinggi apabila melakukan kegiatan yang tidak disukai secara berulang-ulang, remaja menyukai hal-hal baru yang membuat ia tertantang dan membuat individu tersebut ingin melakukan kegiatan baru tersebut. Tentang aktivitas remaja dalam bentuk olahraga kesehatan (Sutrisno, 2015) mengemukakan bahwa olahraga pada remaja sangat sulit dilakukan apabila tidak didorong oleh keinginan yang kuat dari individu itu sendiri dan juga lingkungan sekitarnya, ini berarti remaja akan melakukan kegiatan olahraga apabila ia memiliki minat dan keinginan yang kuat untuk melakukannya. Motivasi remaja biasanya didorong oleh keluarga dan juga lingkungan yang baik agar memberikan konstribusi yang besar agar remaja gemar melakukannya. Ini membuktikan bahwa remaja akan melakukan sesuatu apabila ia di dorong oleh sesuatu yang membuat ia terpacu untuk melakukannya. Menurut penelitian (Yusnistatih, 2018), mengenai gambaran motivasi remaja tentang olah raga, dimana terdapat 40 responden hasil penelitian menunjukkan bahwa dalam kategori rendah berjumlah 18 orang (45,2\%), angka ini menunjukkan bahwa motivasi remaja dalam kategori rendah. Menurut asumsi peneliti maka peneliti beranggapan bahwa motivasi remaja untuk mengikuti kegiatan senam jantung sehat dalam katagori rendah di pengaruhi beberapa faktor yang menjadi tolak ukur dasar yaitu kurangnya minat remaja dipengaruhi oleh lingkungan, kesadaran akan menjaga kesehatan dan juga kurangnya keinginan individu untuk melakukan olahraga senam yang pada dasarnya untuk kebugaran tubuh remaja itu sendiri. Ini di buktikan kurangnya jumlah remaja yang ikut serta dalam melakukan kegiatan senam jantung sehat yang rutin di lakukan di lapangan Blang 
Journal of Healthcare Technology and Medicine Vol. 5 No. 2 Oktober 2019

Universitas Ubudiyah Indonesia

e-ISSN : 2615-109X

Padang tersebut. Senam jantung sehat alangkah baik nya di ikuti rutin oleh remaja sehingga remaja dapat merasakan manfaat dari senam jantung sehat itu sendiri.

\section{KESIMPULAN}

Berdasarkan hasil penelitian dan pembahasan maka dapat disimpulkan sebagai berikut.

1. Motivasi remaja dalam melakukan kegiatan senam jantung sehat pada hari minggu di lapangan Blang Padang berada dalam katagori rendah

2. Motivasi Intrinsik remaja dalam melakukan kegiatan senam jantung sehat di lapangan Blang Padang Banda Aceh berada pada kategori tinggi

3. Motivasi ekstrinsik remaja dalam melakukan kegiatan senam jantung sehat di lapangan Blang Padang berada pada kagori rendah.

\section{SARAN}

Berdasarkan kesimpulan dari hasil penelitian, perlu dibentuk atau dibangun motivasi remaja dalam melakukan senam jantung sehat, baik secara instriksik maupun ekstrinsik, berupa perubahan suasana senam, bentuk senam, gerakan senam yang tidak menoton (gerakan yang sama tiap kali senam). Diperlukan adanya rangsangan bagi pelaku senam berupa hadiah / door prise, bagi peserta yang melakukan gerakan yang baik, pakaian yang serasi dan kegiatan sampingan lainnya sehingga peserta tertarik untuk ikut serta. Perlu adanya penyuluhan tentang pentingnya senam jantung sehat dalam rangka menjaga kesehatan, khususnya kesehatan jantung.

\section{DAFTAR PUSTAKA}

Ahyarmuchlis, (2016). Prinsip Gaya Motivasi. Laweyan, Era Intermedia, Solo. Andelia, (2016). Mengenal Masa Remaja, Aditya Media, Yogyakarta.

Halim, (2015). Minat Remaja Dalam Melakukan Kegiatan Olahraga. Jurnal Preventif Medice.

Kusumah, (2014). Ragam Senam Kebugaran. Indonesia Tera, Magelang. Muchlis, (2015). Motivasi Positif Yang Harus Ditanamkan. Salemba Medika, Jakarta. Sardiman, (2017). Mengenal Motivasi Anak. Dunia Ilmu, Solo.

Sudoyo, (2017). Perbedaan Minat Bakat Seseorang. Salemba Medika, Jakarta

Suniyanti, (2017). Ragam Senam Bagi Usia Remaja Dan Dewasa. Ilmu Semesta, Magelang. Sutrisno, (2015). Senam Bagi Usia Emas. Salemba Medika, Jakarta.

Wanda, (2016). Usia Platinum Menentukan Minat Ragam Kesuksesan. Dunia Ilmu, Solo Yunistatih, (2018). Faktor-Faktor Yang Mempengaruhi Usia Dalam Olahraga Kebugaran. Jurnal medicine of sporty. 